\title{
Dental Sciences, Clinical
}

National Cancer Institute

\section{Source}

National Cancer Institute. Dental Sciences, Clinical. NCI Thesaurus. Code C18731.

The branches of dentistry concerned with the observation and treatment of patients. 